\title{
An analysis of the efficiency of financial support for agriculture in Liaoning
}

\section{Province under the DEA model}

\author{
Li Qiu \\ Shenyang Agricultural University, \\ Shenyang, Liaoning, 110866 \\ Liaoning Shihua university , \\ Fushun, Liaoning, 113001
}

\author{
Wang Chun-ping, \\ Shenyang Agricultural University, \\ Shenyang, Liaoning, 110866 \\ ${ }^{*}$ Corresponding author
}

Abstract - In this paper, the Liaoning Province as the object of study, of the funds of financial expenditure for agriculture in Liaoning Province efficiency were studied. At the same time, the application of principal component analysis method (PCA) to deal with all kinds of data, as far as possible to eliminate the correlation between variables, to ensure the application of DEA model to measure the financial support for agricultural capital using efficiency and accuracy of the results. And the use of DEA method, mainly through the VRS model to calculate efficiency value, obtain the scale efficiency, technical efficiency and pure technical efficiency. The whole analysis mainly includes two aspects. Firstly, it analyses the DEA model, index and data; secondly, the study in the DEA model, Liaoning Province fiscal fund efficiency of agriculture, so that the relevant personnel to accurately understand the situation of the use of funds in Liaoning Province.

Keywords -DEA model, Liaoning province, Financial support for agriculture, Fund efficiency.

\section{INTRODUCTION}

Agriculture belongs to a weak industry in domestic, the capital turnover is slow, relatively long production cycle not only because of the natural environment restricted, but also because the market price movements restricted. In addition, agriculture is facing market and natural risk, leading to the development is limited. And compared with other industries, resource protection and absorb resources ability is relatively weak, comparative advantage is low, agricultural development risk is relatively large. Although China is a big country in agricultural production, in the long process of development, the overall level of agricultural get significantly improved. But farmers are still in more difficult situation as the cause of social development and infrastructure is relatively backward and investment is inadequate, which is unable to meet the needs of the development of modern agriculture; agricultural industrialization system detached; domestic agricultural social service system is not perfect, resulting in many problems in fiscal expenditure management; scattered agricultural production and operation. The problem for the need of agricultural conservation and government intervention has a decisive role, therefore, we need to provide national governments with public financial support, and promote the prosperity and development of the rural economy. 


\section{The background and significance of the efficiency analysis of financial support for agriculture under the DEA model}

Our country belongs to the agricultural development in big country, China's basic national conditions determines agriculture is not only the basis for the survival of 14 million people, but also the basis for the development of the national economy. Since the reform and opening up, more attention has been attached on the agricultural development, especially in recent years, government has paid more and more attention on the problems of agriculture, rural areas and farmers. In this context, the Liaoning provincial government gradually comes to understand the importance of agriculture to develop national economy ${ }^{[1]}$. In the eleventh five year period, Liaoning Province will continue to implement the deregulation, the Central Committee of the Communist Party of China, implement the policy of the national government financial support for agriculture, increase investment in the financial support of the efforts. Under the support of government of Liaoning Province. Agricultural Industry has made rapid development, have laid a solid foundation for the 12th Five Year Plan. But because of Liaoning Province agricultural environment is bad, the agricultural development in the province needs a lot of money. In addition, agriculture has the characteristics of public goods, which requires financial support ${ }^{[2]}$ [3].

\section{DEA data, models and metrics}

The data envelopment analysis method (Data Envelopment Analysis, DEA) is mainly based on the relative efficiency evaluation method established by Cooper and Chames in $1978^{[4]}$.In the process of efficiency evaluation, no need to consider the specific forms of function, not because the output, input data dimension constraints, but are more suitable for the variety of output and input relative efficiency evaluation. As the main purpose of this paper is efficiency evaluation with multiple constraint conditions, the choice of data envelopment analysis method, DEA research ${ }^{[5]}$, fully considering the operating index, importance and can be acquired. Choose narrow fiscal agricultural income as the input indicators, which is agricultural fiscal expenditure of Liaoning Province Statistics Yearbook and China Statistical Yearbook, choosing the ecological benefit, economic benefit and social benefit of output, mainly includes the management of soil and water loss in the area, gross output value of farming, forestry, animal husbandry and fishery and rural households per capita income ${ }^{[6] .}$

Due to the fiscal policy sometimes lag, the role of national policies also need a lot of time. Therefore, it is necessary to select lag phase processing and put into the selection of indicators from the data from 2001 to 2010 , and output indicators select data from 2001 to 2011. In 2007 the implementation of government revenue and expenditure classification reform and statistical yearbook of the financial account also produced changes. It also cancels the fiscal statistics for agricultural expenditure and changes into spending on agriculture, forestry and water affairs, in the fiscal situation analysis in Liaoning Province Statistics Yearbook from 2007 to 2011, and the proportion adjust of actual expenditure of agriculture, forestry and water affairs, you can get indicators of the data. The specific information can be seen from the table one 
Table one: Capital input and output data of financial support for agriculture

\begin{tabular}{|c|c|c|c|c|}
\hline Particular year & $\begin{array}{l}\text { Financial investment in } \\
\text { agriculture }\end{array}$ & $\begin{array}{l}\text { Gross output value of } \\
\text { Farming Forestry Animal } \\
\text { Husbandry and fishery }\end{array}$ & Rural per capita income & $\begin{array}{l}\text { Soil erosion } \\
\text { control area / sq } \\
\mathrm{km}\end{array}$ \\
\hline 2001 & 468603 & 1046 & 2558 & 49001 \\
\hline 2002 & 500220 & 1133 & 2751 & 51010 \\
\hline 2005 & 932200 & 1672 & 3690 & 57003 \\
\hline 2006 & 966220 & 1738 & 4090 & 59002 \\
\hline 2007 & 1218003 & 2130 & 4773 & 60001 \\
\hline 2008 & 1494102 & 2477 & 5577 & 61002 \\
\hline 2009 & 2407102 & 2705 & 5960 & 62110 \\
\hline
\end{tabular}

4. Discussion on the efficiency of financial support for agriculture in Liaoning Province

\subsection{Study on the financial support for agriculture in Liaoning}

The study mainly from ecological benefit, economic benefit and social benefit on financial support for agriculture output can meet the level of analysis, application from the software of the Liaoning Province area of soil erosion, agriculture, forestry, animal husbandry and fishery output and farmer household per capita income three indicators of the implementation of projection analysis and specific operation results from table 2 can be seen. In the economic benefit index can be seen in 2001-2011, eleven decision unit is output in a year, but there is potential for growth; and in terms of social benefit index, 11 each decision making unit among a total of Four decision unit of output; eco efficiency indicators, lack of a decision-making unit of output, output and $0.03 \%$ deficit. 
Table two: 2001 - 2011 Liaoning financial support for agriculture projection analysis

\begin{tabular}{lllllll}
\hline $\begin{array}{l}\text { particular } \\
\text { year }\end{array}$ & $\begin{array}{l}\text { Gross output value of farming, Per capita income in rural areas } \\
\text { forestry, animal } \\
\text { fishery }\end{array}$ & $\begin{array}{l}\text { Improved } \\
\text { target } \\
\text { value/million }\end{array}$ & $\begin{array}{l}\text { target } \\
\text { proportion/\% } \\
\text { value/yuan }\end{array}$ & $\begin{array}{l}\text { Improved } \\
\text { proportion/\% }\end{array}$ & target value/km & $\begin{array}{l}\text { Improved } \\
\text { proportion/\% }\end{array}$ \\
\hline 2001 & 1046 & 0 & 2558 & 3.3 & 49001 & 0 \\
\hline 2002 & 1133 & 0 & 2751 & 2.2 & 51010 & 0 \\
\hline 2003 & 1220 & 0 & 2934 & 0 & 55002 & 0 \\
\hline 2004 & 1511 & 0 & 3307 & 0 & 56001 & 0 \\
\hline 2005 & 1672 & 0 & 3690 & 0 & 57003 & 0 \\
\hline 2006 & 1738 & 11.9 & 4090 & 7.7 & 59002 & 0 \\
\hline 2007 & 2130 & 0 & 4773 & 0 & 60001 & 0 \\
\hline 2009 & 2477 & 0 & 5577 & 0 & 61002 & 0 \\
\hline 2010 & 3105 & 0 & 5960 & 0 & 62110 & 0 \\
\hline 2011 & 3634 & 0 & 6908 & 2.2 & 63002 & 0.3 \\
\hline
\end{tabular}

4.2 The efficiency of financial support for agriculture in Liaoning under the DEA model

Data was obtained in accordance with the above principles, calculated through software deap2.1. The overall efficiency of fiscal support for agriculture in Liaoning Province from 2001 to 2011, which is also called technical efficiency integrated efficiently. If comprehensive efficiency value is 1 , indicating that the DEA is more effective, financial support for agriculture funds can be fully applied; if a comprehensive efficiency values smaller than 1, for example: efficiency value equal to $0.5,50 \%$ of financial support for agriculture proved effective use of funds, $50 \%$ of financial support for agriculture is wasted on behalf of DEA invalid, the overall efficiency is equal to the size multiplied by the efficiency of a purely technical efficiency, it can be decomposed into a comprehensive analysis of the efficiency scale efficiency and pure technical efficiency research. Typically, the main representative of the purely technical and management policies and other factors for financial support for agriculture efficiency, efficiency and scale efficiency of the main representatives of financial support for agriculture affected if the size of the integrated efficiency is not good enough, mainly because of relatively low efficiency due to purely technical, therefore, we need to improve policy and management reforms on purely technic. At the same time a relatively low scale efficiency will affect the overall efficiency, which requires the size to be adjusted in order to improve overall efficiency.

Running results show the eleven DMU is DEA invalid, and efficiency of the integrated value decreased from 0.7 to 0.3 from 2001 to 2010; pure technical effective year is six years, about $54.5 \%$, the efficiency value of the change is relatively stable; and scale efficiency value is always in a relatively low level. In 2011, only 0.3. After data analysis, Liaoning Province shows that the efficiency of fiscal fund for assisting agriculture needs to improve, eleven years in DEA are all invalid, especially in 2011, the comprehensive efficiency of numerical was only 0.3 , about $60 \%$ of the funds of financial agriculture was wasted; pure technical effective 
is Only about half of the shares, fully prove that the Liaoning province does not effectively use financial support for agriculture 。

\section{Suggestions on the use and management of financial support for agriculture in Liaoning Province}

From software running results and conclusions are given several suggestions in accordance with: first, funds of financial support for agriculture. In recent years, Liaoning Province agricultural financial investment were more and more diversified and finance supporting agriculture fund using appears out of touch with the disintegration, resulting in not effectively play the financial function ${ }^{[7]}$.

Second, the financial support of the management and use of funds are in the period of diminishing returns to scale. Therefore, it is necessary that the use and management of financial support for agriculture to innovate, also to increase fiscal agriculture fund investment proportion. From the operation result of the financial fund for agriculture can be seen, the financial fund for agriculture investment of Liaoning Province increases small, which leads to the cause of diminishing returns to scale as the expand of capital investment resulting in capital operation impeded and in the output of a serious shortage.

Third, the fiscal funds investment and direction adjustment increase famers' subsidies, and the input of financial funds for agriculture. It not only increases the proportion of agricultural production support and rural science and technology, but also increases the income of rural people. It can not only promote the development of rural economy of Liaoning Province, and to promote the development of the national economy ${ }^{[8]}$.

\section{Conclusion}

In summary, the results of the efficiency evaluation of the financial expenditure for agriculture in Liaoning Province during the period from 2001 to 2011 can be seen, the funds of financial expenditure for agriculture in Liaoning province actual utilization are always showing a downward trend. In 11 years, the overall efficiency of the financial expenditure for agriculture in Liaoning Province by 0.7 in 2001 dropped to 0.3 in 2011 , about $60 \%$ of the government finance supporting agriculture fund wre wasted. After a comprehensive analysis of the comprehensive efficiency, resulting in the efficiency of financial expenditure for agriculture in Liaoning Province decline due to the lack of fiscal support for agriculture funds scale. In addition, during the period from 2001 to 2011 in Liaoning fiscal funds has not been effectively used, as the government Agriculture capital efficiency was not high, which led by the problem of not enough money. Therefore, in order to promote the development of agricultural economy in Liaoning Province, we need to expand investment in the funds of financial support for agriculture, which can not only promote the development of agriculture in Liaoning Province, but also to improve the level of the national economy of Liaoning Province.

\section{References}

[1] Wulan. China's western regions financial investment in science and technology: scale, structure and efficiency analysis -- Taking Inner Mongolia as an example, Chinese public administration, vol.23:04, pp.90-94, 2014.

[2] Lin Shoufu. Evaluation and analysis of the efficiency of fiscal employment expenditure: An Empirical Study of the DEA Journal of 
Fujian University of science and technology of Donghua province based on, Journal of Donghua University of Science \& Technology (SOCIAL SCIENCE EDITION), vol.14:01, pp.28-33, 2013.

[3] Cheng Kai. Fujian Province fiscal decentralization and based financial education expenditure efficiency -- Based on DEA Malmquist index analysis method, Journal of Fujian Normal University(PHILOSOPHY AND SOCIAL SCIENCES EDITION), vol.21:03, pp.86-91, 2013.

[4] Liu Anxue, Zhang Ying, Chen Xiaoru. Analysis of the efficiency of agricultural comprehensive development expenditure efficiency in agriculture based on DEA, Journal of Xi'an Institute of Finance and Economics, vol.14:05, pp.78-84, 2014.

[5] Yang Junru, Wan Sha. Coupling analysis of food security, farmers' income and the efficiency of financial support for agriculture -- An Empirical Study Based on the DEA original Tobit model, Journal of Hubei University of Economics, vol.23:04, pp.68-71, 2013.

[6] Liu Zifei, Wang Changhai. Three stage DEA analysis of the efficiency of organic agriculture production -- a case study of Yangxian County in Shaanxi, China population, resources and environment, vol.25:03, pp.105-112, 2015

[7] Song Yuanyuan, Yang Wanqiu, Hu Hongwei. Evaluation and influence factors of the rural pension insurance coverage: Based on the DEA and Tobit two step method, Journal of Huazhong Agricultural University (SOCIAL SCIENCE EDITION), vol.15:01, pp.84-89, 2013.

[8] Li Degang, Zhou Li. Empirical analysis of the performance of local fiscal expenditure in Xinjiang -- Based on the two relative benefit model of DEA, Local financial research, vol.25:03, pp.63-67, 2013.. 